\title{
Consensus Interferon: Tailored Therapy and the Impact of Adherence
}

\author{
Stevan A. Gonzalez
}

Published online: 23 January 2011

(C) Springer Science+Business Media, LLC 2011

A successful course of antiviral therapy in patients with chronic hepatitis $\mathrm{C}$ virus (HCV) infection is durable and can result in significant long-term benefit; however, many patients who undergo combination therapy with pegylated interferon alfa (PegIFN) and ribavirin (RBV) ultimately fail and develop persistent viremia. Our ability to achieve a sustained virologic response (SVR) is especially limited in patients with genotype 1 infection. Additional factors that characterize the most challenging subgroups of treatment candidates include those with advanced fibrosis or cirrhosis, fatty liver disease, increased age, obesity, and African American ethnicity [1-6]. Based on several large prospective randomized clinical trials, the rates of SVR associated with genotype 1 infection have ranged from 41 to $52 \%[1-3,5]$. These studies have demonstrated further reductions in SVR to as low as $35 \%$ in genotype 1 patients with a high viral load $[2,3,5]$.

In an effort to increase the potential of achieving an SVR while optimizing adherence to therapy, various strategies have emerged with an emphasis towards an individualized approach. Although some data are conflicting, proposed strategies have included a shortened duration of treatment in subsets of patients with favorable characteristics, including low baseline serum HCV RNA levels and rapid virologic response (RVR) during therapy [7-17]. Alternatively, a key strategy applicable to patients with genotype 1 infection is the extension of treatment duration

S. A. Gonzalez ( $\square)$

Division of General and Transplant Hepatology, Baylor

Regional Transplant Institute, Baylor All Saints Medical Center, 1250 8th Avenue, Suite 515, Fort Worth, TX 76104, USA

e-mail: stevan.gonzalez@baylorhealth.edu based on the timing of viral clearance, in which patients with a slow virologic response may receive up to 72 weeks of therapy [17-22].

Other strategies have involved the use of alternative and potentially more potent forms of interferon-based therapy. Although higher doses of PegIFN and RBV may result in more rapid viral suppression and an increase in SVR, this appears to occur at the cost of decreased tolerability as demonstrated in a recent prospective study [23]. Consensus interferon (CIFN) has emerged as a viable treatment option in both naïve and previously treated patients with chronic $\mathrm{HCV}$, particularly in those with difficult-to-treat characteristics. CIFN is a synthetic type I interferon protein that comprises a consensus sequence of the most common amino acids found in naturally occurring alpha interferon subtypes. Initial in vitro studies suggested that CIFN has superior antiviral efficacy in comparison with interferon alfa (IFN) [24], while prospective clinical data have reported a significant increase in SVR for genotype 1 patients with high viral load treated with CIFN versus standard IFN [25, 26]. Although comparative data are limited, one study suggests that CIFN may be as effective as PegIFN when used in combination with RBV for the treatment of genotype 1 patients [27]. A long-acting form of CIFN is not available; however, daily dosing may further enhance viral suppression [28] and has been shown to be an effective dosing strategy in a large prospective clinical trial of patients who failed prior PegIFN and RBV therapy [29].

In this issue of Digestive Diseases and Sciences, Ho and colleagues present their experience with a tailored approach to therapy in a cohort of treatment-naïve genotype 1 patients with difficult-to-treat characteristics, utilizing strategies including extended treatment duration and the use of high-dose daily CIFN (15 mcg) in combination 
with RBV [30]. This study population of mostly VA patients included a significant proportion with high viral load, advanced fibrosis, and African American ethnicity. Patients were randomized to receive either a 1-year course of daily CIFN and RBV or a variable duration of therapy. In the variable duration arm, an additional 48 weeks of daily CIFN and RBV was administered following achievement of a virologic response within the first 24 weeks, defined as a $>2-\log$ reduction or undetectable serum HCV RNA.

As a pilot study emphasizing tolerability and efficacy, the findings reported by Ho et al. [5, 31] are limited by relatively small numbers; however, several key issues should be highlighted. The overall intention to treat SVR based on pooled data from both treatment arms is comparable to reports from studies involving PegIFN and RBV in genotype 1 populations with high viral loads and advanced fibrosis. As expected, achievement of viral clearance early during the course of therapy in this cohort was associated with an increase in SVR; yet extension of treatment duration did not appear to enhance the rate of virologic response in slow responders. As the authors point out, a major factor associated with this observation was the high rate of discontinuation due to adverse events or noncompliance in $50 \%$ of patients overall and in $40 \%$ within the first 24 weeks of therapy. Consequently, only a minority of patients actually reached completion of an extended course.

Early discontinuation of therapy due to adverse events or noncompliance has been noted in previous prospective studies involving daily dosing of CIFN plus RBV. In one small clinical trial of CIFN 9 mcg daily plus RBV, over one-third of treatment-naïve patients were unable to complete the expected course of therapy [32]. In the DailyDose Consensus Interferon and Ribavirin: Efficacy of Combined Therapy (DIRECT) trial, over $20 \%$ of treatment-experienced patients who previously failed courses of PegIFN and RBV were reported to discontinue therapy due to adverse events or loss to follow-up (Fig. 1) [29]. Higher doses of CIFN have been associated with an increased likelihood of discontinuation and dose reductions due to adverse events [33], which may be a contributing factor to the high rate of early discontinuation observed by Ho et al. An additional factor includes the increased proportion of patients with advanced fibrosis. However, the wide variation in discontinuation rates among study sites, as noted by the authors, suggests the presence of external or local factors influencing adherence within this study population. In contrast with daily CIFN and RBV, early discontinuation associated with combination PegIFN and RBV has been reported in the range of $13-16 \%$ [1-3, 5], although rates may be increased in patients with cirrhosis [31].

Despite the low overall SVR, a striking finding in this study was the high SVR reported in the small proportion of

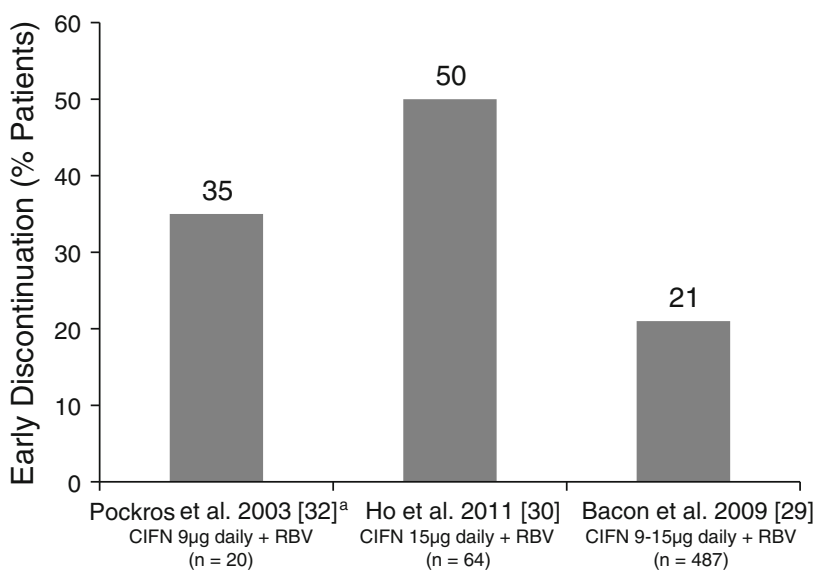

Fig. 1 Treatment discontinuation in prospective randomized clinical trials of daily consensus interferon and ribavirin for 48 weeks in genotype 1 chronic hepatitis C. Overall rates of early discontinuation are shown as reported from prospective clinical trials involving treatment-naïve $[30,32]$ as well as treatment-experienced patients [29]. Discontinuation occurred for reasons not related to virologic response. Factors resulting in discontinuation shown here include adverse events, noncompliance, and loss to follow up. ${ }^{\mathrm{a}}$ Data only shown from treatment arm receiving combination $C I F N$ and $R B V$. $C I F N$ consensus interferon, $R B V$ ribavirin

patients (20\%) who maintained adherence with at least $80 \%$ of the CIFN dose, $80 \%$ of the RBV dose, and $80 \%$ of the expected duration of therapy (80/80/80 adherence). The importance of adherence in achieving SVR is well established, particularly in patients with genotype 1 infection. Although direct comparisons were not made, the SVR noted in this minority of patients who were adherent $(85 \%)$ was greater than what has been reported in adherent genotype 1 patients receiving PegIFN and RBV (51-63\%) [34]. Albeit promising, this finding is limited by a small sample size.

Altogether, these results emphasize the impact of adherence on virologic response as well as the challenges encountered with potent antiviral therapy requiring highfrequency dosing regimens. CIFN therapy may indeed result in more successful outcomes in challenging populations, yet virologic response rates may be sacrificed by decreased tolerability associated with the daily administration of higher therapeutic doses. An additional point highlighted by this study is that loss of adherence may result in failure of other strategies, such as extended treatment duration, that would otherwise be utilized in a tailored approach.

Ultimately, larger prospective studies will be required to more accurately determine the role of high-dose daily CIFN and RBV in difficult-to-treat populations. A key factor in optimizing outcomes associated with CIFN may involve the selection of candidates with the greatest likelihood of completing a full course of therapy. In the future, direct acting antiviral agents (DAA) will likely add another dimension to the individualized approach to HCV therapy, in which the duration may be altered significantly based on 
early treatment responses [35-37]. Whether high-dose daily CIFN therapy will emerge as a key player in combination with DAA for specific subsets of challenging patients has yet to be determined; however, adherence will remain a critical factor.

\section{References}

1. Manns MP, McHutchison JG, Gordon SC, et al. Peginterferon $a l f a-2 b$ plus ribavirin compared with interferon alfa- $2 b$ plus ribavirin for initial treatment of chronic hepatitis $\mathrm{C}$ : a randomised trial. Lancet. 2001;358:958-965.

2. Fried MW, Shiffman ML, Reddy KR, et al. Peginterferon alfa-2a plus ribavirin for chronic hepatitis $\mathrm{C}$ virus infection. $N$ Engl $J$ Med. 2002;347:975-982.

3. Hadziyannis SJ, Sette H Jr, Morgan TR, et al. Peginterferonalpha2a and ribavirin combination therapy in chronic hepatitis $\mathrm{C}$ : a randomized study of treatment duration and ribavirin dose. Ann Intern Med. 2004;140:346-355.

4. Muir AJ, Bornstein JD, Killenberg PG. Peginterferon alfa-2b and ribavirin for the treatment of chronic hepatitis $\mathrm{C}$ in blacks and non-Hispanic whites. $N$ Engl J Med. 2004;350:2265-2271.

5. McHutchison JG, Lawitz EJ, Shiffman ML, et al. Peginterferon alfa-2b or alfa-2a with ribavirin for treatment of hepatitis $\mathrm{C}$ infection. N Engl J Med. 2009;361:580-593.

6. Conjeevaram HS, Fried MW, Jeffers LJ, et al. Peginterferon and ribavirin treatment in African American and Caucasian American patients with hepatitis C genotype 1. Gastroenterology. 2006; 131:470-477.

7. Mangia A, Santoro R, Minerva N, et al. Peginterferon alfa- $2 b$ and ribavirin for 12 verses 24 weeks in HCV genotype 2 or 3. N Engl J Med. 2005;352:2609-2617.

8. von Wagner M, Huber M, Berg T, et al. Peginterferon-alpha-2a (40KD) and ribavirin for 16 or 24 weeks in patients with genotype 2 or 3 chronic hepatitis C. Gastroenterology. 2005;129: 522-527.

9. Dalgard O, Bjoro K, Hellum KB, et al. Treatment with pegylated interferon and ribavarin in HCV infection with genotype 2 or 3 for 14 weeks: a pilot study. Hepatology. 2004;40:1260-1265.

10. Yu ML, Dai CY, Huang JF, et al. A randomised study of peginterferon and ribavirin for 16 versus 24 weeks in patients with genotype 2 chronic hepatitis C. Gut. 2007;56:553-559.

11. Shiffman ML, Suter F, Bacon BR, et al. Peginterferon alfa-2a and ribavirin for 16 or 24 weeks in HCV genotype 2 or 3. $N$ Engl J Med. 2007;357:124-134.

12. Lagging M, Langeland N, Pedersen $\mathrm{C}$, et al. Randomized comparison of 12 or 24 weeks of peginterferon alpha-2a and ribavirin in chronic hepatitis $\mathrm{C}$ virus genotype $2 / 3$ infection. Hepatology. 2008;47:1837-1845.

13. Mangia A, Minerva N, Bacca D, et al. Determinants of relapse after a short (12 weeks) course of antiviral therapy and re-treatment efficacy of a prolonged course in patients with chronic hepatitis C virus genotype 2 or 3 infection. Hepatology. 2009;49: 358-363.

14. Zeuzem S, Buti M, Ferenci P, et al. Efficacy of 24 weeks treatment with peginterferon alfa- $2 \mathrm{~b}$ plus ribavirin in patients with chronic hepatitis $\mathrm{C}$ infected with genotype 1 and low pretreatment viremia. J Hepatol. 2006;44:97-103.

15. Jensen DM, Morgan TR, Marcellin P, et al. Early identification of HCV genotype 1 patients responding to 24 weeks peginterferon alpha-2a (40 kd)/ribavirin therapy. Hepatology. 2006;43:954960 .
16. Yu ML, Dai CY, Huang JF, et al. Rapid virological response and treatment duration for chronic hepatitis $\mathrm{C}$ genotype 1 patients: a randomized trial. 2008;47:1884-1893.

17. Mangia A, Minerva N, Bacca D, et al. Individualized treatment duration for hepatitis $\mathrm{C}$ genotype 1 patients: a randomized controlled trial. Hepatology. 2008;47:43-50.

18. Berg $\mathrm{T}$, von Wagner $\mathrm{M}$, Nasser $\mathrm{S}$, et al. Extended treatment duration for hepatitis $\mathrm{C}$ virus type 1 : comparing 48 versus 72 weeks of peginterferon-alfa-2a plus ribavirin. Gastroenterology. 2006;130:1086-1097.

19. Sanchez-Tapias JM, Diago M, Escartin P, et al. Peginterferonalfa2a plus ribavirin for 48 versus 72 weeks in patients with detectable hepatitis C virus RNA at week 4 of treatment. Gastroenterology. 2006;131:451-460.

20. Pearlman BL, Ehleben C, Saifee S. Treatment extension to 72 weeks of peginterferon and ribavirin in hepatitis $\mathrm{C}$ genotype 1-infected slow responders. Hepatology. 2007;46:1688-1694.

21. Ferenci P, Laferl H, Scherzer TM, et al. Peginterferon alfa-2a/ ribavirin for 48 or 72 weeks in hepatitis C genotypes 1 and 4 patients with slow virologic response. Gastroenterology. 2010; 138:503-512.

22. Buti M, Lurie Y, Zakharova NG, et al. Randomized trial of peginterferon alfa- $2 \mathrm{~b}$ and ribavirin for 48 or 72 weeks in patients with hepatitis $\mathrm{C}$ virus genotype 1 and slow virologic response. Hepatology. 2010;52:1201-1207.

23. Fried MW, Jensen DM, Rodriguez-Torres $M$, et al. Improved outcomes in patients with hepatitis $\mathrm{C}$ with difficult-to-treat characteristics: randomized study of higher doses of peginterferon alpha-2a and ribavirin. Hepatology. 2008;48:1033-1043.

24. Blatt LM, Davis JM, Klein SB, Taylor MW. The biologic activity and molecular characterization of a novel synthetic interferonalpha species, consensus interferon. J Interferon Cytokine Res. 1996;16:489-499.

25. Jensen DM, Krawitt EL, Keeffe EB, et al. Biochemical and viral response to consensus interferon (CIFN) therapy in chronic hepatitis C patients: effect of baseline viral concentration. Consensus interferon study group. Am J Gastroenterol. 1999;94: 3583-3588.

26. Sjogren $\mathrm{MH}$, Sjogren R, Holtzmuller $\mathrm{K}$, et al. Interferon alfacon1 and ribavirin versus interferon alpha- $2 b$ and ribavirin in the treatment of chronic hepatitis C. Dig Dis Sci. 2005;50:727-732.

27. Sjogren MH, Sjogren R Jr, Lyons MF, et al. Antiviral response of $\mathrm{HCV}$ genotype 1 to consensus interferon and ribavirin versus pegylated interferon and ribavirin. Dig Dis Sci. 2007;52: $1540-1547$.

28. Rustgi VK, Bonkovsky HL, Arora S, Zeuzem SP, Manns M, Blatt LM. Daily versus three-times-weekly IFN Alfacon-1 in previously untreated $\mathrm{HCV}$ patients results in a significantly greater rate of SVR: Final results of an international, phase 4 study [abstract]. Gastroenterology. 2005;128:A-A716.

29. Bacon BR, Shiffman ML, Mendes F, et al. Retreating chronic hepatitis $\mathrm{C}$ with daily interferon alfacon-1/ribavirin after nonresponse to pegylated interferon/ribavirin: DIRECT results. Hepatology. 2009;49:1838-1846.

30. Ho SB, Aqel B, Dieperink E, et al. (2011) US multicenter pilot study of daily consensus interferon (CIFN) plus ribavirin for "difficult-to-treat" HCV genotype 1 patients. Dig Dis Sci (in press).

31. Bruno S, Shiffman ML, Roberts SK, et al. Efficacy and safety of peginterferon alfa-2a (40KD) plus ribavirin in hepatitis $\mathrm{C}$ patients with advanced fibrosis and cirrhosis. Hepatology. 2010;51: 388-397.

32. Pockros PJ, Reindollar R, McHutchinson J, et al. The safety and tolerability of daily infergen plus ribavirin in the treatment of naive chronic hepatitis C patients. J Viral Hepat. 2003;10:55-60. 
33. Fattovich G, Zagni I, Minola E, et al. A randomized trial of consensus interferon in combination with ribavirin as initial treatment for chronic hepatitis C. J Hepatol. 2003;39:843-849.

34. McHutchison JG, Manns M, Patel K, et al. Adherence to combination therapy enhances sustained response in genotype-1infected patients with chronic hepatitis C. Gastroenterology. 2002;123:1061-1069.

35. McHutchison JG, Everson GT, Gordon SC, et al. Telaprevir with peginterferon and ribavirin for chronic HCV genotype 1 infection. N Engl J Med. 2009;360:1827-1838.
36. Hezode C, Forestier N, Dusheiko G, et al. Telaprevir and peginterferon with or without ribavirin for chronic HCV infection. N Engl J Med. 2009;360:1839-1850.

37. Kwo PY, Lawitz EJ, McCone J, et al. Efficacy of boceprevir, an NS3 protease inhibitor, in combination with peginterferon alfa- $2 b$ and ribavirin in treatment-naive patients with genotype 1 hepatitis C infection (SPRINT-1): an open-label, randomised, multicentre phase 2 trial. Lancet. 2010;376:705-716. 